\title{
Microbacterium paraoxydans
}

National Cancer Institute

\section{Source}

National Cancer Institute. Microbacterium paraoxydans. NCI Thesaurus. Code C86512.

A species of aerobic, Gram positive, coryneform bacteria assigned to the phylum Actinobacteria. This species is motile, nonfermentative, forms yellow pigmented colonies, catalase positive, oxidase negative and hydrolyzes esculin and gelatin. M. paraoxydans is pathogenic and one of the most common species of Microbacterium to be isolated from clinical specimens. 